\title{
Promoção do crescimento do feijoeiro e controle da antracnose por Trichoderma spp.
}

\author{
Erica Aparecida de Souza Pedro(1), Ricardo Harakava(2), Cleusa Maria Mantovanello Lucon ${ }^{(2)}$ \\ e Sylvia Dias Guzzo(2)
}

\begin{abstract}
(1)In memoriam (2)Instituto Biológico, Centro de Pesquisa e Desenvolvimento de Sanidade Vegetal, Laboratório de Bioquímica Fitopatológica, Caixa Postal 12.898, CEP 04010-970 São Paulo, SP. E-mail: harakava@biologico.sp.gov.br, mantova@biologico.sp.gov.br, guzzo@biologico.sp.gov.br
\end{abstract}

\begin{abstract}
Resumo - O objetivo deste trabalho foi avaliar a capacidade de Trichoderma spp. em promover o crescimento de plantas de feijão e reduzir a severidade da antracnose do feijoeiro (Colletotrichum lindemuthianum), bem como identificar os isolados mais eficientes. Sessenta isolados de Trichoderma spp. foram avaliados quanto à capacidade de promoção do crescimento nas plantas. Os sete isolados que mais se destacaram foram adicionados ao substrato de cultivo e avaliados quanto à redução na severidade da antracnose em plantas de feijão tratadas com conídios de $C$. lindemuthianum. Os mais eficientes no controle da doença foram identificados por sequenciamento de DNA. O isolado IB 28/07 foi avaliado nas concentrações $0,5,1,1,5$ e 2\% (peso:volume), que reduziram a severidade da doença em $41,51,55,15,81,82$ e $96,06 \%$, respectivamente. Os isolados mais eficientes de Trichoderma spp. podem proporcionar aumentos superiores a 30\% na produção de matéria seca da parte aérea das plantas e reduzir a severidade da doença entre 63 e $98 \%$. Esses isolados foram identificados como pertencentes às espécies Trichoderma harzianum, T. strigosum e T. theobromicola.
\end{abstract}

Termos para indexação: Colletotrichum lindemuthinum, bioprospecção, controle biológico, resistência sistêmica, sequenciamento de DNA.

\section{Plant growth promotion of common bean and anthracnose control by Trichoderma spp.}

\begin{abstract}
The objective of this work was to evaluate the ability of Trichoderma spp. to promote growth of common bean plants and to reduce severity of anthracnose (Colletotrichum lindemuthianum), as well as to identify the best performing isolates. Sixty Trichoderma spp. isolates were evaluated as to their capacity to promote growth in common bean. The seven isolates that stood out were added to the culture substrate and assessed for reduction in severity of anthracnose in bean plants treated with $C$. lindemuthianum conidia. The most efficient isolates in controlling the disease were identified by DNA sequencing. The IB 28/07 isolate was evaluated in the concentrations $0.5,1,1.5$, and $2 \%$ (weight:volume), which reduced disease severity in 41.51 , $55.15,81.82$, and $96.06 \%$, respectively. The most efficient Trichoderma spp. isolates can promote increases above $30 \%$ in dry matter production and reduce disease severity between 63 and $98 \%$. These isolates were identified as belonging to the species Trichoderma harzianum, T. strigosum, and T. theobromicola.
\end{abstract}

Index terms: Colletotrichum lindemuthianum, bioprospection, biological control, systemic resistance, DNA sequencing.

\section{Introdução}

A antracnose do feijoeiro, causada pelo fungo Colletotrichum lindemuthianum (Sacc \& Magn), é uma das doenças mais importantes da cultura, pois reduz a produção e a qualidade dos grãos (Chiorato et al., 2006). As perdas causadas pela doença podem chegar a $100 \%$, principalmente quando são utilizadas sementes infectadas e as condições de temperatura e umidade relativa do ar são favoráveis (Vechiato et al., 2001).
A aplicação indiscriminada de defensivos agrícolas pode ter efeito deletério sobre o meio ambiente e a saúde humana, bem como levar ao surgimento de fitopatógenos resistentes aos produtos rotineiramente empregados (Naseby et al., 2000). Portanto, há grande relevância no estudo de métodos alternativos de controle de pragas e doenças. Neste sentido, o controle biológico pode contribuir para reduzir o impacto da agricultura no ambiente (Gaur \& Sharmam, 2010). 
Espécies do gênero Trichoderma vêm sendo utilizadas com sucesso no controle de fitopatógenos, por serem capazes de proteger plantas por meio de mecanismos como parasitismo, antibiose, competição por nutrientes e substrato, e indução de resistência. Além disso, essas espécies colonizam com facilidade o sistema radicular e promovem o crescimento de diversas espécies de plantas (Woo et al., 2006; Vinale et al., 2008). Estudos de emprego de Trichoderma spp. no controle de doenças de plantas têm focalizado os efeitos diretos deste antagonista sobre fitopatógenos. No entanto, a indução de resistência de plantas também tem sido considerada um mecanismo relevante (Yoshioka et al., 2012).

O objetivo deste trabalho foi avaliar a capacidade de Trichoderma spp. em promover o crescimento de plantas de feijão (Phaseolus vulgaris L.) e reduzir a severidade da antracnose do feijoeiro, bem como avaliar e identificar as espécies dos isolados mais eficientes.

\section{Material e Métodos}

Os experimentos foram realizados no laboratório e casa de vegetação do Laboratório de Bioquímica Fitopatológica do Instituto Biológico, em Campinas, SP, no período de março de 2010 a janeiro de 2012.

Foram utilizados 60 isolados de Trichoderma spp. pertencentes à Coleção de Culturas do Laboratório de Bioquímica Fitopatológica do Instituto Biológico. Os inóculos dos isolados foram produzidos, separadamente, em sacos de plástico de polipropileno transparentes, contendo grãos de arroz umedecidos e autoclavados, mantidos em câmara tipo BOD por sete dias a: $25 \pm 2{ }^{\circ} \mathrm{C}$, fotoperíodo de 12 horas de luz e escuro (Papavizas, 1982; Silva, 1997). Para obtenção do inóculo de $C$. lindemuthianum, raça 65 (14313-65 NPAF- Embrapa), o fungo foi cultivado em placas contendo meio Mathur (Rey et al., 2005). A suspensão aquosa foi preparada pela remoção dos conídios da superfície do meio de cultura com água destilada esterilizada. A concentração foi ajustada com auxílio de microscópio óptico e câmara de Neubauer para $1 \times 10^{6}$ conídios $\mathrm{mL}^{-1}$.

No ensaio de promoção de crescimento, realizado em casa de vegetação, os 60 isolados de Trichoderma spp. foram adicionados, separadamente, ao substrato Tropstrato HT (Vida Verde, Mogi Mirim, SP), utilizado no cultivo de feijão 'Pérola'. A infestação foi feita pela adição de $20 \mathrm{~g}$ de arroz colonizado pelos isolados de Trichoderma spp. (em média 3,7x109 conídios por grama de arroz), em cada litro de substrato. Sacos transparentes contendo a mistura de substrato e inóculo foram incubados por sete dias em temperatura ambiente. Após este período, a mistura foi homogeneizada e distribuída em sacos pretos de polietileno (300 g por saco). O plantio foi feito com cinco sementes de feijão 'Pérola' por saco. Foram utilizadas cinco repetições, o que totalizou 25 plantas por tratamento. No tratamento controle, realizou-se a adição de arroz sem o crescimento de microrganismos. O ensaio foi repetido três vezes em 2010: uma vez em março e duas em abril. A avaliação do ensaio foi feita 15 dias após o plantio, quando a parte aérea das plantas foi removida e submetida à secagem em estufa por 72 horas, a $70^{\circ} \mathrm{C}$, até obtenção da massa de matéria seca constante. Utilizou-se o delineamento inteiramente casualizado, com cinco repetições de cinco plantas cada uma. A massa do sistema radicular não foi avaliada, tendo-se optado pela medição da parte aérea apenas, que reflete o bom desenvolvimento do sistema radicular (Björkman et al., 1998).

Para avaliar o efeito dos isolados de Trichoderma spp. na severidade da doença, grãos de arroz colonizados com os sete isolados de Trichoderma spp. que mais se destacaram no teste de promoção de crescimento, com aumentos superiores a $30 \%$ na produção de matéria seca das plantas de feijão, foram adicionados, separadamente, na proporção de $2 \%$ (peso:volume), próximos à base de plantas de feijão com 15 dias de idade. A concentração de Trichoderma spp. utilizada no ensaio foi determinada pela quantificação do número de conídios, por meio de diluição seriada de amostras de $1 \mathrm{~g}$ de arroz colonizado em $9 \mathrm{~mL}$ de solução salina a $0,9 \%$, e contagem dos conídios em microscópio ótico. As concentrações de conídios variaram de 1,4 a $5,6 \times 10^{9}$ conídios por grama de arroz colonizado. Como controle, empregou-se arroz comercial sem Trichoderma spp inserido no substrato.

Sete dias após a inoculação com Trichoderma spp., a parte aérea das plantas foi inoculada por aspersão de suspensão aquosa de conídios de $C$. lindemuthianum $\left(1 \times 10^{6}\right.$ conídios $\left.\mathrm{mL}^{-1}\right)$. As plantas foram mantidas por 48 horas em câmara úmida com fotoperíodo de 12 horas e, em seguida, deixadas em temperatura ambiente. Foram utilizadas dez plantas por tratamento. Sete dias após a inoculação com o patógeno, foi 
avaliada a severidade da doença, em duas folhas por planta, pela quantificação da área foliar lesionada por meio do programa Quanti V. 1.0, para quantificação de doenças de plantas, da Universidade Federal de Viçosa (Vale et al., 2001). A severidade da doença foi expressa em percentagem de área lesionada. A proteção foi calculada como redução da severidade da doença e expressa como percentagem do controle, de acordo com Moraes et al. (1976).

O isolado IB 28/07 foi selecionado aleatoriamente entre os isolados com melhores resultados nos ensaios de promoção de crescimento e redução de severidade da doença para avaliação do efeito de diferentes concentrações do inóculo. As concentrações de $0,5,1$, 1,5 e $2 \%$ (peso:volume) desse isolado foram adicionadas próximo à base das plantas de feijão com 15 dias de idade, sete dias antes da inoculação do patógeno $\left(1 \times 10^{6}\right.$ conídios $\mathrm{mL}^{-1}$ ). A avaliação da severidade da doença foi realizada da mesma forma descrita anteriormente.

Os sete isolados de Trichoderma spp. que mais se destacaram nos ensaios de promoção de crescimento e na redução da severidade da doença foram submetidos ao sequenciamento gênico para a identificação das espécies. A extração de DNA foi realizada conforme Murray \& Thompson (1980). Para a reação em cadeia da polimerase (PCR), foram utilizados os pares de iniciadores ITS 1 (5' TCCGTWGGTGAACCWGC 3') e ITS 4 (5' TCCTCCGCTTATTGATATGC 3'), que amplificam a região espaçadora entre os genes ribossomais 18S e 26S (White et al., 1990). A reação foi conduzida em termociclador PTC-100 (MJ Research Inc., Watertown, MA, EUA), e as temperaturas e os tempos de incubação foram de: $94^{\circ} \mathrm{C}$ por $2 \mathrm{~min}$; 40 ciclos de $94^{\circ} \mathrm{C}$ por $15 \mathrm{~s}, 56^{\circ} \mathrm{C}$ por $30 \mathrm{~s}, 72^{\circ} \mathrm{C}$ por $30 \mathrm{~s} ; 72^{\circ} \mathrm{C}$ por 4 min e $4^{\circ} \mathrm{C}$ até a utilização das amostras. Os fragmentos de DNAamplificados foram purificados e submetidos à reação de sequenciamento com o reagente Big Dye Terminator 3.1 (Applied Biosystems, Foster City, CA, EUA), pelo método de terminação de cadeia (Sanger et al., 1977), e analisados em sequenciador automático ABI 377 (Applied Biosystems, Foster City, CA, EUA). As sequências de nucleotídeos foram submetidas aos programas TrichoBlast e TrichOkey, disponíveis em International Subcommission on Trichoderma and Hypocrea Taxonomy (2011), que permitem realizar a identificação molecular de fungos do gênero Trichoderma, por meio da comparação com sequências de espécies "vouchers" (Druzhinina et al., 2005; Kopchinskiy et al., 2005; Nagy et al., 2007).

Todos os experimentos foram repetidos três vezes. Os dados obtidos foram submetidos à análise de variância e comparados pelo teste de Duncan e Tukey, a $1 \%$ de probabilidade, com uso do programa Assistat, versão 7.5 Beta (Silva \& Azevedo, 2002).

\section{Resultados e Discussão}

No primeiro ensaio de promoção de crescimento, 54 isolados de Trichoderma spp., dos 60 avaliados, causaram aumentos significativos na produção de matéria seca das plantas de feijão, quando comparados ao tratamento controle (Tabela 1). A magnitude dos incrementos esteve entre 3,12 (IB 47/02) e 57,81\% (IB 30/07). No segundo ensaio, 42 isolados aumentaram significativamente a massa de matéria seca das plantas de feijão, com variações entre 4,65\% (IB 01/03 e IB 34/08) e $34,88 \%$ (IB 51/09). No terceiro ensaio, 53 isolados causaram aumentos significativos entre $3,70 \%$ (IB 01/01) e 57,41\% (IB 43/14).

Carvalho et al. (2011) testaram o efeito de seis isolados de Trichoderma spp. no crescimento de plantas de feijão e observaram que quatro deles proporcionaram aumentos na massa de matéria seca da parte aérea das plantas entre 4,42 e 5,71\%, percentagens semelhantes aos menores aumentos verificados no presente trabalho. Segundo Brotman et al. (2010), espécies de Trichoderma podem promover aumentos de até 300\% no crescimento de plantas. O efeito benéfico desses fungos tem sido relatado no desenvolvimento de várias culturas de importância, como mamoeiro, tomateiro, soja, milho, pepineiro, pimentão e eucalipto (Carvalho Filho et al., 2008; Tavares, 2009; Fontenelle et al., 2011; Silva et al., 2011). Os aumentos na produção de matéria seca podem variar de acordo com o isolado de Trichoderma utilizado e a cultura. Tavares (2009) constatou incremento da massa de matéria seca de mudas de mamoeiro de até $110,73 \%$, enquanto Fontenelle et al. (2011) verificaram aumentos de até $1.244,83 \%$ em tomateiro. Aumentos expressivos, entre 57 e 136\%, também foram observados em Eucalyptus urophilla (Carvalho Filho et al., 2008).

O efeito de Trichoderma spp. no crescimento de plantas tem sido relacionado a diversos fatores, tais como proteção de plantas contra patógenos primários e secundários da rizosfera, produção de hormônios 
Tabela 1. Massa de matéria seca (MS) de plantas de feijão crescidas em substrato, com incorporação de 60 isolados de Trichoderma spp., em condições de casa de vegetação(1).

\begin{tabular}{|c|c|c|c|c|c|c|}
\hline \multirow[t]{2}{*}{$\overline{\text { Isolados }^{(2)}}$} & \multicolumn{2}{|c|}{ Primeiro ensaio } & \multicolumn{2}{|c|}{ Segundo ensaio } & \multicolumn{2}{|c|}{ Terceiro ensaio } \\
\hline & Massa de MS $(\mathrm{g})^{(3)}$ & Crescimento (\%) ${ }^{(4)}$ & Massa de MS (g) & Crescimento $(\%)$ & Massa de MS (g) & Crescimento (\%) \\
\hline IB 01/01 & $0,121 \pm 0,002 \mathrm{pq}$ & $-5,47$ & $0,125 \pm 0,004 \mathrm{fg}$ & $-3,10$ & $0,112 \pm 0,004 \mathrm{de}$ & 3,70 \\
\hline IB 01/03 & $0,119 \pm 0,005 q$ & $-7,03$ & $0,135 \pm 0,006 b c$ & 4,65 & $0,125 \pm 0,005 b c$ & 15,74 \\
\hline IB 01/04 & $0,122 \pm 0,011 \mathrm{op}$ & $-4,69$ & $0,137 \pm 0,003 b c$ & 6,20 & $0,128 \pm 0,011 b c$ & 18,52 \\
\hline IB 01/13 & $0,147 \pm 0,009 \mathrm{de}$ & 14,84 & $0,116 \pm 0,015 \mathrm{ij}$ & $-10,08$ & $0,129 \pm 0,016 b c$ & 19,44 \\
\hline IB $02 / 05$ & $0,130 \pm 0,0181 \mathrm{~m}$ & 1,56 & $0,138 \pm 0,005 \mathrm{ab}$ & 6,98 & $0,135 \pm 0,006 b c$ & 25,00 \\
\hline IB 04/04 & $0,150 \pm 0,007 \mathrm{de}$ & 17,19 & $0,147 \pm 0,013 \mathrm{ab}$ & 13,95 & $0,142 \pm 0,011 \mathrm{ab}$ & 31,48 \\
\hline IB 04/05 & $0,133 \pm 0,010 \mathrm{ij}$ & 3,91 & $0,134 \pm 0,009 \mathrm{~cd}$ & 3,88 & $0,109 \pm 0,012 \mathrm{fg}$ & 0,92 \\
\hline IB 04/08 & $0,134 \pm 0,011 \mathrm{ij}$ & 4,69 & $0,133 \pm 0,002 \mathrm{de}$ & 3,10 & $0,114 \pm 0,013 \mathrm{de}$ & 5,55 \\
\hline IB 04/09 & $0,138 \pm 0,004 \mathrm{hi}$ & 7,81 & $0,139 \pm 0,011 \mathrm{ab}$ & 7,75 & $0,119 \pm 0,006 b c$ & 10,18 \\
\hline IB 07/01 & $0,149 \pm 0,008 \mathrm{de}$ & 16,41 & $0,155 \pm 0,007 \mathrm{ab}$ & 20,16 & $0,116 \pm 0,007 \mathrm{~cd}$ & 7,41 \\
\hline IB 07/06 & $0,167 \pm 0,012 b c$ & 30,47 & $0,144 \pm 0,011 \mathrm{ab}$ & 11,63 & $0,133 \pm 0,013 b c$ & 23,15 \\
\hline IB 07/10 & $0,165 \pm 0,006 \mathrm{bc}$ & 28,91 & $0,151 \pm 0,005 \mathrm{ab}$ & 17,05 & $0,124 \pm 0,008 \mathrm{bc}$ & 14,81 \\
\hline IB 07/14 & $0,181 \pm 0,011 \mathrm{ab}$ & 41,41 & $0,150 \pm 0,015 \mathrm{ab}$ & 16,28 & $0,123 \pm 0,009 b c$ & 13,89 \\
\hline IB 08/07 & $0,172 \pm 0,006 \mathrm{ab}$ & 34,38 & $0,128 \pm 0,004 \mathrm{ef}$ & $-0,78$ & $0,119 \pm 0,008 \mathrm{bc}$ & 10,18 \\
\hline IB 08/08 & $0,161 \pm 0,006 \mathrm{~cd}$ & 25,78 & $0,128 \pm 0,009 \mathrm{ef}$ & $-0,78$ & $0,117 \pm 0,010 \mathrm{~cd}$ & 8,33 \\
\hline IB 09/02 & $0,158 \pm 0,005 \mathrm{~cd}$ & 23,44 & $0,126 \pm 0,018 \mathrm{fg}$ & $-2,32$ & $0,128 \pm 0,009 b c$ & 18,52 \\
\hline IB 11/09 & $0,152 \pm 0,011 \mathrm{de}$ & 18,75 & $0,112 \pm 0,008 \mathrm{jl}$ & $-13,18$ & $0,104 \pm 0,011 \mathrm{gh}$ & $-3,70$ \\
\hline IB $14 / 05$ & $0,145 \pm 0,006 \mathrm{ef}$ & 13,28 & $0,130 \pm 0,008 \mathrm{de}$ & 0,78 & $0,119 \pm 0,011 b c$ & 10,18 \\
\hline IB $18 / 03$ & $0,142 \pm 0,006 f g$ & 10,94 & $0,107 \pm 0,0021$ & $-17,05$ & $0,121 \pm 0,010 b c$ & 12,04 \\
\hline IB 19/17 & $0,129 \pm 0,014 \mathrm{~lm}$ & 0,78 & $0,171 \pm 0,012 \mathrm{ab}$ & 32,56 & $0,151 \pm 0,008 \mathrm{ab}$ & 39,81 \\
\hline IB 20/02 & $0,154 \pm 0,005 \mathrm{~cd}$ & 20,31 & $0,155 \pm 0,008 \mathrm{ab}$ & 20,16 & $0,131 \pm 0,002 b c$ & 21,30 \\
\hline IB 26/08 & $0,123 \pm 0,007$ no & $-3,91$ & $0,156 \pm 0,013 \mathrm{ab}$ & 20,93 & $0,130 \pm 0,014 b c$ & 20,37 \\
\hline IB 26/10 & $0,137 \pm 0,007 \mathrm{hi}$ & 7,03 & $0,166 \pm 0,018 \mathrm{ab}$ & 28,68 & $0,136 \pm 0,010 \mathrm{bc}$ & 25,92 \\
\hline IB 28/05 & $0,190 \pm 0,008 \mathrm{ab}$ & 48,44 & $0,147 \pm 0,007 \mathrm{ab}$ & 13,95 & $0,120 \pm 0,009 b c$ & 11,11 \\
\hline IB $28 / 07$ & $0,177 \pm 0,007 \mathrm{ab}$ & 38,28 & $0,151 \pm 0,016 \mathrm{ab}$ & 17,05 & $0,143 \pm 0,008 \mathrm{ab}$ & 32,41 \\
\hline IB 28/09 & $0,172 \pm 0,012 \mathrm{ab}$ & 34,38 & $0,153 \pm 0,007 \mathrm{ab}$ & 18,60 & $0,146 \pm 0,009 \mathrm{ab}$ & 35,18 \\
\hline IB $28 / 15$ & $0,169 \pm 0,004 \mathrm{ab}$ & 32,03 & $0,150 \pm 0,010 \mathrm{ab}$ & 16,28 & $0,129 \pm 0,004 b c$ & 19,44 \\
\hline IB 29/08 & $0,182 \pm 0,006 \mathrm{ab}$ & 42,19 & $0,139 \pm 0,005 \mathrm{ab}$ & 7,75 & $0,111 \pm 0,013 \mathrm{ef}$ & 2,78 \\
\hline IB 30/06 & $0,197 \pm 0,019 \mathrm{ab}$ & 53,91 & $0,164 \pm 0,020 \mathrm{ab}$ & 27,13 & $0,145 \pm 0,013 \mathrm{ab}$ & 34,26 \\
\hline IB 30/07 & $0,202 \pm 0,013 \mathrm{a}$ & 57,81 & $0,152 \pm 0,005 \mathrm{ab}$ & 17,83 & $0,153 \pm 0,005 \mathrm{ab}$ & 41,67 \\
\hline IB $31 / 03$ & $0,188 \pm 0,008 \mathrm{ab}$ & 46,88 & $0,144 \pm 0,022 \mathrm{ab}$ & 11,63 & $0,103 \pm 0,008 \mathrm{~h}$ & $-4,63$ \\
\hline IB 31/06 & $0,166 \pm 0,007 b c$ & 29,69 & $0,144 \pm 0,010 \mathrm{ab}$ & 11,63 & $0,127 \pm 0,007 b c$ & 17,59 \\
\hline IB 32/03 & $0,155 \pm 0,006 \mathrm{~cd}$ & 21,09 & $0,137 \pm 0,009 \mathrm{ab}$ & 6,20 & $0,126 \pm 0,008 b c$ & 16,67 \\
\hline IB 32/06 & $0,163 \pm 0,014 b c$ & 27,34 & $0,147 \pm 0,006 \mathrm{ab}$ & 13,95 & $0,120 \pm 0,011 b c$ & 11,11 \\
\hline IB 34/01 & $0,173 \pm 0,011 \mathrm{ab}$ & 35,16 & $0,147 \pm 0,004 \mathrm{ab}$ & 13,95 & $0,117 \pm 0,008 \mathrm{~cd}$ & 8,33 \\
\hline IB 34/04 & $0,160 \pm 0,013 \mathrm{~cd}$ & 25,00 & $0,139 \pm 0,006 \mathrm{ab}$ & 7,75 & $0,110 \pm 0,007 \mathrm{ef}$ & 1,85 \\
\hline IB 34/06 & $0,148 \pm 0,014$ de & 15,62 & $0,169 \pm 0,007 \mathrm{ab}$ & 31,00 & $0,121 \pm 0,013 b c$ & 12,04 \\
\hline IB 34/08 & $0,145 \pm 0,008 \mathrm{ef}$ & 13,28 & $0,135 \pm 0,009 \mathrm{bc}$ & 4,65 & $0,105 \pm 0,009 \mathrm{gh}$ & $-2,78$ \\
\hline IB 35/04 & $0,146 \pm 0,017 \mathrm{de}$ & 14,06 & $0,152 \pm 0,011 \mathrm{ab}$ & 17,83 & $0,116 \pm 0,012 \mathrm{~cd}$ & 7,41 \\
\hline IB 37/01 & $0,144 \pm 0,012 \mathrm{fg}$ & 12,50 & $0,165 \pm 0,012 \mathrm{ab}$ & 27,91 & $0,136 \pm 0,004 b c$ & 25,92 \\
\hline IB 38/11 & $0,133 \pm 0,008 \mathrm{ij}$ & 3,91 & $0,155 \pm 0,004 a b$ & 20,16 & $0,127 \pm 0,009 b c$ & 17,59 \\
\hline IB 40/07 & $0,139 \pm 0,013 \mathrm{gh}$ & 8,59 & $0,152 \pm 0,007 \mathrm{ab}$ & 17,83 & $0,134 \pm 0,009 b c$ & 24,07 \\
\hline IB 40/08 & $0,136 \pm 0,008 \mathrm{ij}$ & 6,25 & $0,131 \pm 0,006 \mathrm{de}$ & 1,55 & $0,126 \pm 0,011 b c$ & 16,67 \\
\hline IB $42 / 03$ & $0,156 \pm 0,010 \mathrm{~cd}$ & 21,88 & $0,132 \pm 0,004 \mathrm{de}$ & 2,32 & $0,121 \pm 0,013 b c$ & 12,04 \\
\hline IB $42 / 15$ & $0,150 \pm 0,004 \mathrm{de}$ & 17,19 & $0,122 \pm 0,007 \mathrm{gh}$ & $-5,43$ & $0,138 \pm 0,014 \mathrm{ab}$ & 27,78 \\
\hline IB $43 / 14$ & $0,175 \pm 0,005 \mathrm{ab}$ & 36,72 & $0,117 \pm 0,012 \mathrm{hi}$ & $-9,30$ & $0,170 \pm 0,015 \mathrm{a}$ & 57,41 \\
\hline IB 46/08 & $0,141 \pm 0,004 \mathrm{fg}$ & 10,16 & $0,140 \pm 0,009 \mathrm{ab}$ & 8,53 & $0,137 \pm 0,009 b c$ & 26,85 \\
\hline IB $46 / 10$ & $0,149 \pm 0,012 \mathrm{de}$ & 16,41 & $0,123 \pm 0,006 \mathrm{gh}$ & $-4,65$ & $0,146 \pm 0,010 \mathrm{ab}$ & 35,18 \\
\hline IB $47 / 02$ & $0,132 \pm 0,012 \mathrm{j} 1$ & 3,12 & $0,132 \pm 0,014 \mathrm{de}$ & 2,32 & $0,129 \pm 0,007 b c$ & 19,44 \\
\hline IB 47/06 & $0,151 \pm 0,009$ de & 17,97 & $0,127 \pm 0,013 \mathrm{fg}$ & $-1,55$ & $0,124 \pm 0,007 b c$ & 14,81 \\
\hline IB 47/09 & $0,157 \pm 0,012 \mathrm{~cd}$ & 22,66 & $0,134 \pm 0,007 \mathrm{~cd}$ & 3,88 & $0,128 \pm 0,012 b c$ & 18,52 \\
\hline IB 48/06 & $0,159 \pm 0,009 \mathrm{~cd}$ & 24,22 & $0,141 \pm 0,014 \mathrm{ab}$ & 9,30 & $0,120 \pm 0,008 b c$ & 11,11 \\
\hline IB 48/11 & $0,166 \pm 0,005 b c$ & 29,69 & $0,120 \pm 0,008 \mathrm{gh}$ & $-6,98$ & $0,132 \pm 0,010 \mathrm{bc}$ & 22,22 \\
\hline IB $48 / 13$ & $0,163 \pm 0,019 b c$ & 27,34 & $0,139 \pm 0,015 \mathrm{ab}$ & 7,75 & $0,141 \pm 0,011 \mathrm{ab}$ & 30,55 \\
\hline IB $49 / 15$ & $0,152 \pm 0,009 \mathrm{de}$ & 18,75 & $0,151 \pm 0,007 \mathrm{ab}$ & 17,05 & $0,118 \pm 0,010 \mathrm{bc}$ & 9,26 \\
\hline IB 49/16 & $0,159 \pm 0,017 \mathrm{~cd}$ & 24,22 & $0,149 \pm 0,011 \mathrm{ab}$ & 15,50 & $0,128 \pm 0,007 b c$ & 18,52 \\
\hline IB 49/17 & $0,148 \pm 0,010 \mathrm{de}$ & 15,62 & $0,148 \pm 0,008 \mathrm{ab}$ & 14,73 & $0,120 \pm 0,007 b c$ & 11,11 \\
\hline IB 50/20 & $0,177 \pm 0,010 \mathrm{ab}$ & 38,28 & $0,136 \pm 0,013 b c$ & 5,43 & $0,106 \pm 0,004 \mathrm{gh}$ & $-1,85$ \\
\hline IB 51/07 & $0,164 \pm 0,007 \mathrm{bc}$ & 28,12 & $0,162 \pm 0,013 \mathrm{ab}$ & 25,58 & $0,142 \pm 0,007 \mathrm{ab}$ & 31,48 \\
\hline IB 51/09 & $0,152 \pm 0,012 \mathrm{de}$ & 18,75 & $0,174 \pm 0,007 \mathrm{a}$ & 34,88 & $0,150 \pm 0,012 \mathrm{ab}$ & 38,89 \\
\hline Controle & $0,128 \pm 0,005 \mathrm{mn}$ & & $0,129 \pm 0,015 \mathrm{de}$ & & $0,108 \pm 0,009 \mathrm{fg}$ & \\
\hline$\overline{\mathrm{CV}}(\%)$ & 14,84 & & 16,10 & & 17,18 & \\
\hline
\end{tabular}

${ }^{(1)}$ Médias seguidas por letras iguais não diferem pelo teste de Duncan, a $1 \%$ de probabilidade. ${ }^{(2)}$ Isolados de Trichoderma spp. incorporados ao substrato Tropstrato HT. ${ }^{(3)}$ Média \pm erro-padrão da massa de matéria seca da parte aérea das plantas, em gramas $(\mathrm{n}=5) .{ }^{(4)}$ Aumento de crescimento, determinado em relação ao controle, calculado como acréscimo na massa de matéria seca da parte aérea das plantas de feijão e expresso como percentagem.

Pesq. agropec. bras., Brasília, v.47, n.11, p.1589-1595, nov. 2012 
de crescimento de plantas, aumento da absorção e da translocação de nutrientes minerais, e aumento da solubilidade e da disponibilidade de vários micronutrientes (Yedidia et al., 2001).

Os sete isolados com melhor performance nas avaliações de promoção do crescimento (IB 19/17, IB 28/07, IB 28/09, IB 30/06, IB 30/07, IB 43/14 e IB 51/09), que proporcionaram aumentos na massa de matéria seca da parte aérea superiores a $30 \%$, conferiram proteção à antracnose quando adicionados uma semana antes da inoculação do patógeno, com percentagens de proteção que variaram entre 77,60 e 97,54\% (Tabela 2). De acordo com Sriram et al. (2009), linhagens selecionadas de espécies de Trichoderma são potentes indutores de respostas de defesa em plantas. De Meyer et al. (1998) aplicaram T. harzianum T30 no solo, sete dias antes da inoculação de Botrytis cinerea em alface, tomate, pimentão, fumo e feijão, e observaram reduções significativas do mofo-cinzento em todas as culturas. Nas plantas de feijão, os autores relataram redução de $35 \%$ na severidade da doença, e, como não encontraram o isolado T30 nas folhas, eles atribuíram a redução dos sintomas da doença à indução de resistência ativada pelo antagonista. A proteção de plantas de feijão por T. harzianum foi relatada por Abeysinghe (2009), que utilizou o isolado RU01 adicionado ao solo sete dias antes da inoculação de Uromyces appendiculatus, agente causador da ferrugem do feijoeiro. As reduções observadas na severidade da doença variaram de 44 a 47\%. Sriram

Tabela 2. Severidade da antracnose (Colletotrichum lindemuthianum) em feijoeiro cultivado em substrato infestado com isolados de Trichoderma spp.$^{(1)}$.

\begin{tabular}{|c|c|c|}
\hline Tratamentos $^{(2)}$ & Área foliar lesionada por planta & Redução da severidade ${ }^{(3)}$ \\
\hline & $---(\%)^{(4)}$ & - \\
\hline Controle & $12,99 \pm 2,01 \mathrm{a}$ & - \\
\hline IB 51/09 & $2,91 \pm 1,02 b$ & 77,60 \\
\hline IB $43 / 14$ & $2,88 \pm 1,05 b$ & 77,83 \\
\hline IB 28/09 & $1,77 \pm 0,63 \mathrm{bc}$ & 86,37 \\
\hline IB 30/07 & $1,24 \pm 0,43 \mathrm{bc}$ & 90,45 \\
\hline IB $19 / 17$ & $0,81 \pm 0,40 \mathrm{bc}$ & 93,76 \\
\hline IB $28 / 07$ & $0,44 \pm 0,17 \mathrm{bc}$ & 96,61 \\
\hline IB 30/06 & $0,32 \pm 0,06 \mathrm{c}$ & 97,54 \\
\hline $\mathrm{CV}(\%)$ & 53,31 & \\
\hline $\begin{array}{l}\text { (1) Médias } \pm \text { erro- } \\
\text { Tukey, a } 1 \% \text { d } \\
\text { incorporados a } \\
\text { de C. lindemu } \\
\text { transformados }\end{array}$ & $\begin{array}{l}\text {-padrão seguidas por letras iguais } \\
\text { de probabilidade }(\mathrm{n}=10) .{ }^{(2)} \text { Isola } \\
\text { ao substrato Tropstrato HT, sete } \\
\text { uthianum. }{ }^{(3)} \text { Determinada em rela } \\
\text { pela função } \sqrt{x} \text {. }\end{array}$ & $\begin{array}{l}\text { não diferem pelo teste de } \\
\text { ados de Trichoderma spp. } \\
\text { dias antes da inoculação } \\
\text { ação ao controle. }{ }^{(4)} \text { Dados }\end{array}$ \\
\hline
\end{tabular}

et al. (2009) constataram reduções entre 48 e $62 \%$, proporcionada por T. harzianum, na infecção causada por Phytophthora capsici, em pimenta vermelha, enquanto Bae et al. (2011) verificaram que o isolado DIS $376 \mathrm{f}$ de $T$. theobromicola foi capaz de atrasar o desenvolvimento de sintomas de doença causados por $P$. capsici em pimentão.

Nos últimos anos, vários trabalhos têm buscado elucidar os mecanismos de proteção de plantas contra fitopatógenos pela aplicação de Trichoderma spp. Segundo Brotman et al. (2010), isolados de Trichoderma spp. colonizam a epiderme e as células do córtex de raízes e, consequentemente, ativam vias de sinalização, o que desencadeia respostas de defesa nas plantas. Salas-Marina et al. (2011) observaram que a colonização de raízes de Arabidopsis por $T$. atroviride induziu a expressão dos genes de defesa PR1, PR2 ( $\beta$-1,3-glucanase), PDF1.2 (defensina) e $L O X-1$ (lipoxigenase), envolvidos nas vias metabólicas do ácido salicílico, do ácido jasmônico e do etileno.

A incorporação de diferentes concentrações do isolado IB 28/07 (T. strigosum) ao substrato e a posterior inoculação das folhas de feijoeiro com C. lindemuthianum resultaram na redução da severidade da doença com o aumento na concentração do fungo (Tabela 3). Todas as concentrações aplicadas conferiram proteção das plantas à antracnose, que variou de 41,51 a $96,06 \%$, sendo que as menores concentrações $(0,5$ e $1 \%$ ) apresentaram redução da severidade da doença significativamente inferior à da maior concentração (2\%). A ação de T. strigosum na proteção de plantas contra fitopatógenos também foi constatada por

Tabela 3. Severidade da antracnose do feijoeiro, em substrato infestado com quatro concentrações do isolado de Trichoderma sp. (IB 28/07), sete dias antes da inoculação de Colletotrichum lindemuthianum ${ }^{(1)}$.

\begin{tabular}{lcc}
\hline $\begin{array}{l}\text { Concentração } \\
\text { do inóculo (\%) }\end{array}$ & Área foliar lesionada por planta & Redução da severidade ${ }^{(2)}$ \\
\hline Controle & $3,30 \pm 0,43 \mathrm{a}$ & - \\
0,5 & $1,93 \pm 0,34 \mathrm{~b}$ & 41,51 \\
1,0 & $1,48 \pm 0,08 \mathrm{bc}$ & 55,15 \\
1,5 & $0,60 \pm 0,02 \mathrm{~cd}$ & 81,82 \\
2,0 & $0,13 \pm 0,40 \mathrm{~d}$ & 96,06 \\
\hline $\mathrm{CV}(\%)$ & 32,57 &
\end{tabular}

${ }^{(1)}$ Médias \pm erro-padrão seguidas por letras iguais não diferem pelo teste de Tukey, a $1 \%$ de probabilidade $(\mathrm{n}=10) .{ }^{(2)}$ Determinada em relação ao controle. ${ }^{(3)}$ Dados transformados por $\sqrt{\mathrm{X}}$. 
Fontenelle et al. (2011). Estes autores verificaram reduções de 83,79 e $93,99 \%$ respectivamente na severidade das doenças causadas por Xanthomonas euvesicatoria e Alternaria solani, em tomateiro. Isolados de Trichoderma spp. são capazes de produzir mais de 100 tipos de compostos bioativos, o que inclui enzimas degradadoras de parede celular, antibióticos e muitas outras substâncias ainda não caracterizadas, as quais podem apresentar propriedades antifúngicas ou atuar como elicitores de respostas de defesa das plantas (Yedidia et al., 2003; Woo \& Lorito, 2007).

Dos sete isolados mais eficientes de Trichoderma spp., cinco (IB 19/17, IB 28/09, IB 30/06, IB 30/07 e IB 51/09) foram identificados como $T$. harzianum, um (IB 28/07) como $T$. strigosum e um (IB 43/14) como T. theobromicola. Os isolados apresentaram similaridade superior a 98\%, em comparação aos isolados "voucher" das bases de dados, para a região ITS, identificados pelo programa TrichOkey. Os resultados obtidos confirmam dados da literatura quanto à capacidade das espécies $T$. harzianum, $T$. strigosum e $T$. theobromicola de promoverem o crescimento de plantas e reduzirem a severidade de doenças causadas por patógenos foliares (Sriram et al., 2009; Bae et al., 2011; Fontenelle et al., 2011; Silva et al., 2011).

\section{Conclusões}

1. Isolados de Trichoderma spp. podem promover o crescimento e reduzir a severidade da antracnose em plantas de feijão 'Pérola', em condições de casa de vegetação.

2. As espécies Trichoderma harzianum, $T$. strigosum e $T$. theobromicola são eficientes na promoção de crescimento de plantas e na proteção do feijoeiro contra a antracnose, causada por Colletotrichum lindemuthianum, em condições de casa de vegetação.

3. Trichoderma strigosum (IB 28/07) confere proteção sistêmica de plantas de feijoeiro 'Pérola' a $C$. lindemuthianum proporcional à concentração de inóculo utilizada, em condições de casa de vegetação.

\section{Agradecimentos}

Ao engenheiro agrônomo Luiz Fukuhara, da Empresa Binova, pelo auxílio financeiro.

\section{Referências}

ABEYSINGHE, S. Systemic resistance induced by Trichoderma harzianum RU01 against Uromyces appendiculatus on Phaseolus vulgaris. Journal of the National Science Foundation of Sri Lanka, v.37, p.203-207, 2009.

BAE, H.; ROBERTS, D.P.; LIM, H.-S.; STREM, M.D.; PARK, S.C.; RYU, C.M.; MELNICK, R.L.; BAILEY, B.A. Endophytic Trichoderma isolates from tropical environments delay disease onset and induce resistance against Phytophthora capsici in hot pepper using multiple mechanisms. Molecular Plant Microbe Interactions, v.24, p.336-351, 2011.

BJÖRKMAN, T.; BLANCHARD, L.M.; HARMAN, G.E. Growth enhancement of shrunken-2 (sh2) sweet corn by Trichoderma harzianum 1295-22: effect of environmental stress. Journal of the American Society for Horticultural Science, v.123, p.35-40, 1998.

BROTMAN, Y.; GUPTA, J.K.; VITERBO, A. Trichoderma. Current Biology, v.20, p.390-391, 2010.

CARVALHO FILHO, M.R.; MELLO, S.C.M. de; SANTOS, R.P. dos; MENÊZES, J.E. Avaliação de isolados de Trichoderma na promoção de crescimento, produção de ácido indolacético in vitro e colonização endofítica de mudas de eucalipto. Brasília: Embrapa Recursos Genéticos e Biotecnologia, 2008. 13p. (Embrapa Recursos Genéticos e Biotecnologia. Boletim de pesquisa e desenvolvimento, 226).

CARVALHO, D.D.C.; MELLO, S.C.M.; LOBO JÚNIOR, M.; SILVA, M.C. Controle de Fusarium oxysporum f. sp. phaseoli in vitro e em sementes, e promoção de crescimento inicial do feijoeiro comum por Trichoderma harzianum. Tropical Plant Pathology, v.36, p.28-34, 2011.

CHIORATO, A.F.; CARBONELL, S.A.M.; MOURA, R.R. de; ITO, M.F.; COLOMBO, C.A. Co-evolução entre raças fisiológicas de Colletotrichum lindemuthianum e feijoeiro. Bragantia, v.65, p.381-388, 2006.

DE MEYER, G.; BIGIRIMANA, J.; ELAD, Y.; HÖFTE, M. Induced systemic resistance in Trichoderma harzianum T39 biocontrol of Botrytis cinerea. European Journal of Plant Pathology, v.104, p.279-286, 1998.

DRUZHININA, I.S.; KOPTCHINSKI, A.G.; KOMOM, M.; BISSETT, J.; SZAKACS, G.; KUBICEK, C.P. An oligonucleotide barcode for species identification in Trichoderma and Hypocrea. Fungal Genetics and Biology, v.42, p.813-828, 2005.

FONTENELLE, A.D.B.; GUZZO, S.D.; LUCON, C.M.M.; HARAKAVA, R. Growth promotion and induction of resistance in tomato plant against Xanthomonas euvesicatoria and Alternaria solani by Trichoderma spp. Crop Protection, v.30, p.1492-1500, 2011.

GAUR, R.B.; SHARMAM, R.N. Biocontrol of root rot in cotton and compatibility of potential bioagents with fungicides. Indian Journal of Plant Protection, v.38, p.176-182, 2010.

KOPCHINSKIY, A.; KOMON, M.; KUBICEK, C.P.; DRUZHININA, I.S. TrichoBLAST: a multilocus database for 
Trichoderma and Hypocrea identifications. Mycological Research, v.109, p.658-660, 2005.

MORAES, W.B.C.; MARTINS, E.M.F.; MUSUMECI, M.R.; BERETTA, M.J.G. Induced protection to Hemileia vastatrix in coffe plants. Summa Phytopathologica, v.2, p.39-43, 1976.

MURRAY, M.G.; THOMPSON, W.F. Rapid isolation of high molecular weight plant DNA. Nucleic Acids Research, v.8, p.4321-4325, 1980.

NAGY, V.; SEIDL, V.; SZAKACS, G.; KOMON-ZELAZOWSKA, M.; KUBICEK, C.P.; DRUZHININA, I.S. Application of DNA bar codes for screening of industrially important fungi: the haplotype of Trichoderma harzianum sensu stricto indicates superior chitinase formation. Applied and Environmental Microbiology, v.73, p.7048-7058, 2007.

NASEBY, D.C.; PASCUAL, J.A.; LYNCH, J.M. Effect of biocontrol strains of Trichoderma on plant growth, Pythium ultimum populations, soil microbial communities and soil enzyme activities. Journal of Applied Microbiology, v.88, p.161-169, 2000.

PAPAVIZAS, G.C. Survival of Trichoderma harzianum in soil and in pea bean rhizospheres. Phytopathology, v.72, p.121-122, 1982.

REY, M. dos S.; BALARDIN, R.S.; PIEROBOM, C.R. Reação de cultivares de feijoeiro comum (Phaseolus vulgaris) a patótipos de Colletotrichum lindemuthianum. Revista Brasileira de Agrociência, v.11, p.113-116, 2005.

SALAS-MARINA, M.A.; SILVA-FLORES, M.A.; URESTI-RIVERA, E.E.; CASTRO-LONGORIA, E.; HERRERA-ESTRELLA, A.; CASAS-FLORES, S. Colonization of Arabidopsis roots by Trichoderma atroviride promotes growth and enhances systemic disease resistance through jasmonic acid/ethylene and salicylic acid pathways. European Journal of Plant Pathology, v.131, p.15-26, 2011.

SANGER, F.; NICKLEN, S.; CHASE, A.R. DNA sequencing with chain terminating inhibitors. Proceedings of the National Academy of Sciences of the United States of America, v.74, p.5463-5468, 1977.

SILVA, A.C.F. Uso de radiação gama para obtenção de mutantes de Trichoderma harzianum Rifai e $T$. viride Pers.Fr com capacidade melhorada no controle de Sclerotinia sclerotiorum (Lib.) de Bary. 1997. 143p. Tese (Doutorado) - Universidade de São Paulo, São Paulo.

SILVA, F. de A.S. e; AZEVEDO, C.A.V. de. Versão do programa computacional Assistat para o sistema operacional Windows. Revista Brasileira de Produtos Agroindustriais, v.4, p.71-78, 2002.

SILVA, V.N. da; GUZZO, S.D.; LUCON, C.M.M.; HARAKAVA, R. Promoção de crescimento e indução de resistência à antracnose por Trichoderma spp. em pepineiro. Pesquisa Agropecuária Brasileira, v.46, p.1609-1618, 2011.
SRIRAM, S.; MANASA, S.B.; SAVITHA, M.J. Potential use of elicitors from Trichoderma in induced systemic resistance for the management of Phytophthora capsici in red pepper. Journal of Biological Control, v.23, p.449-456, 2009.

TAVARES, G.M. Podridão do pé do mamoeiro: infestação em solos de cultivo, controle alternativo com indutores de resistência e Trichoderma e avaliação dos mecanismos de defesa envolvidos. 2009. 113p. Tese (Doutorado) - Universidade Federal Rural de Pernambuco, Recife.

VALE, F.X.R.; FERNANDES FILHO, E.I.; LIBERATO, J.R. Quant: quantificação de doenças. Versão 1.0.1. Viçosa: UFV, 2001.

VECHIATO, M.H.; LASCA, C.C.; KOHARA, E.Y.; CHIBA, S. Antracnose do feijoeiro: tratamento de sementes e correlação entre a incidência em plantas e infecção de sementes. Arquivos do Instituto Biológico, v.68, p.83-87, 2001.

VINALE, F.; SIVASITHAMPARAM, K.; GHISALBERTI, E.L.; MARRA, R.; WOO, S.L.; LORITO, M. Trichoderma-plant-pathogen interactions. Soil Biology and Biochemistry, v.40, p.1-10, 2008.

WHITE, T.J.; BRUNS, T.; LEE, S.; TAYLOR, J. Amplification and direct sequencing of fungal ribosomal RNA genes for phylogenetics. In: INNIS, M.A.; GELFAND, D.H.; SNINSKY, J.J.; WHITE, T.J. (Ed.). PCR protocols: a guide to methods and applications. San Diego: Academic Press, 1990. p.315-322.

WOO, S.L.; LORITO, M. Exploiting the interactions between fungal antagonists, pathogens and the plant for biocontrol. In: VURRO, M.; GRESSEL, J. (Ed.). Novel biotechnologies for biocontrol agent enhancement and management. Amsterdam: Springer, 2007. p.107-130. (NATO security through science series).

WOO, S.L.; SCALA, F.; RUOCCO, M.; LORITO, M. The molecular biology of the interactions between Trichoderma spp., phytopathogenic fungi, and plants. Phytopathology, v.96, p.181-185, 2006.

YEDIDIA, I.; SHORESH, M.; KEREM, Z.; BENHAMOU, N.; KAPULNIK, Y.; CHET, I. Concomitant induction of systemic resistance to Pseudomonas syringae pv. lachrymans in cucumber by Trichoderma asperellum (T-203) and accumulation of phytoalexins. Applied and Environmental Microbiology, v.69, p.7343-7353, 2003.

YEDIDIA, I.; SRIVASTVA, A.K.; KAPULNIK, Y.; CHET, I. Effect of Trichoderma harzianum on microelement concentration and increased growth of cucumber plants. Plant and Soil, v.235, p.235-242, 2001.

YOSHIOKA, Y.; ICHIKAWA, H.; NAZNIN, H.A.; KOGURE, A.; HYAKUMACHI, M. Systemic resistance induced in Arabidopsis thaliana by Trichoderma asperellum SKT-1, a microbial pesticide of seedborne diseases of rice. Pest Management Science, v.68, p.60-66, 2012.

Recebido em 14 de maio de 2012 e aprovado em 3 de outubro de 2012 